\title{
Prehospital cardiopulmonary resuscitation duration and neurological outcome after out-of-hospital cardiac arrest among children by location of arrest: a Nationwide cohort study
}

Haruka Shida', Tasuku Matsuyama ${ }^{2 *}$, Kosuke Kiyohara ${ }^{3}$, Tetsuhisa Kitamura ${ }^{4}$, Takefumi Kishimori ${ }^{1}$, Takeyuki Kiguchi ${ }^{5}$, Chika Nishiyama ${ }^{6}$, Daisuke Kobayashi ${ }^{5}$, Satoe Okabayashi ${ }^{5}$, Tomonari Shimamoto ${ }^{5}$, Takashi Kawamura ${ }^{5}$ and Taku Iwami ${ }^{5}$

\begin{abstract}
Background: Little is known about the associations between the duration of prehospital cardiopulmonary resuscitation (CPR) by emergency medical services (EMS) and outcomes among paediatric patients with out-of-hospital cardiac arrests (OHCAs). We investigated these associations and the optimal prehospital EMS CPR duration by the location of arrests.

Methods: We included paediatric patients aged 0-17 years with OHCAs before EMS arrival who were transported to medical institutions after resuscitation by bystanders or EMS personnel. We excluded paediatric OHCA patients for whom CPR was not performed, who had cardiac arrest after EMS arrival, whose EMS CPR duration were $<0$ min or $\geq 120$ min and who had cardiac arrest in healthcare facilities. Prehospital EMS CPR duration was defined as the time from CPR initiation by EMS personnel to the time of prehospital return of spontaneous circulation or to the time of hospital arrival. The primary outcome was 1-month survival with a favourable neurological outcome (cerebral performance category scale 1 or 2). Statistical analysis was performed with Mann-Whitney $U$ tests for numerical variables and chi-squared test for categorical variables. Univariable and multivariable logistic regression analyses were applied to assess the association between prehospital EMS CPR duration and a favourable neurological outcome, and crude and adjusted odds ratios and their 95\% confidence intervals were calculated.
\end{abstract}

Results: The proportion of patients with a favourable neurological outcome was lower in residential locations than in public locations (2.3\% [66/2865] vs 10.8\% [113/1048]; $P<.001)$. In both univariable and multivariable logistic regression analyses, the proportion of patients with a favourable neurological outcome decreased as prehospital EMS CPR duration increased, regardless of the location of arrests ( $P$ for trend <.001). However, some patients achieved a favourable neurological outcome after a prolonged prehospital EMS CPR duration (> $30 \mathrm{~min}$ ) in both groups (1.4\% [6/417] in residential locations and 0.6\% [1/170] in public locations).

Conclusions: A longer prehospital EMS CPR duration is independently associated with a lower proportion of patients with a favourable neurological outcome. The association between prehospital EMS CPR duration and neurological outcome differed significantly by location of arrests.

Keywords: Cardiac arrest, Paediatric, Prehospital EMS CPR duration, Favourable neurological outcome

\footnotetext{
* Correspondence: task-m@koto.kpu-m.ac.jp

${ }^{2}$ Department of Emergency Medicine, Kyoto Prefectural University of

Medicine, Kyoto, Japan

Full list of author information is available at the end of the article
}

(c) The Author(s). 2019 Open Access This article is distributed under the terms of the Creative Commons Attribution 4.0 International License (http://creativecommons.org/licenses/by/4.0/), which permits unrestricted use, distribution, and reproduction in any medium, provided you give appropriate credit to the original author(s) and the source, provide a link to the Creative Commons license, and indicate if changes were made. The Creative Commons Public Domain Dedication waiver (http://creativecommons.org/publicdomain/zero/1.0/) applies to the data made available in this article, unless otherwise stated. 


\section{Background}

Out-of-hospital cardiac arrest (OHCA) is a critical public health problem in industrialised countries [1-3], and only $3 \%$ of patients with OHCA are paediatric patients; thus, paediatric OHCA is rare compared to OHCA in adults $[4,5]$. Paediatric cardiac arrests occur because of various factors, and numerous previous studies have investigated the association between several prehospital factors such as age and first documented rhythm and survival after paediatric OHCAs [4-9].

Paediatric OHCAs have a significant negative effect on society, especially in terms of the emotional burden of family members, and they have vital implications for medical staff; however, the medical challenges for paediatric OHCA patients have not been sufficiently discussed. Thus, the optimal cardiopulmonary resuscitation (CPR) duration for paediatric OHCA patients is difficult to determine. Although the paediatric CPR guidelines recommend that the decision to terminate CPR must not be based only on CPR duration [10], further evidence is needed to establish the appropriate paediatric CPR duration.

Previous studies demonstrated that bystander CPR and shocks by public-access automated external defibrillators (AEDs) are effective in improving the outcomes of paediatric OHCA patients $[4,11-13]$ and that differences in survival between locations among OHCA patients exist [14-16]. Thus, the location where the arrest occurs plays a role in prehospital CPR duration. The All-Japan Utstein Registry, which is a prospective nationwide, population-based registry of OHCA patients in Japan $[17,18]$, was launched to obtain information including OHCA locations since 2013 and has recorded approximately 4000 paediatric OHCAs that occurred before emergency medical services (EMS) arrival between 2013 and 2015.

This study aimed to investigate the relationship between the duration of prehospital CPR by EMS and 1month survival with a favourable neurological outcome in paediatric OHCAs by location of arrests.

\section{Methods}

\section{Study design, population, and settings}

Details of the All-Japan Utstein Registry of the Fire and Disaster Management Agency (FDMA) of Japan have been previously described $[17,18]$. This is a populationbased observational study using a prospective, nationwide OHCA registry based on the international Utstein Style [19-21]. From this national registry, we extracted information on paediatric patients aged $0-17$ years with OHCA before EMS arrival, who were resuscitated by bystanders or EMS personnel and were subsequently transported to medical institutions from 1 January 2013 to 31 December 2015. This study excluded (1) paediatric
OHCA patients for whom CPR was not performed, (2) who had cardiac arrest after EMS arrival, (3) whose prehospital EMS CPR duration were $<0$ min or $\geq 120 \mathrm{~min}$ and (4) who had cardiac arrest in healthcare facilities. The Ethics Committee of Kyoto Prefectural University of Medicine approved this study. The requirement of written informed consent was waived.

Cardiac arrest was defined as the cessation of cardiac mechanical activity, as evidenced by the absence of circulation signs and as confirmed by EMS personnel [19-21]. The aetiology of cardiac arrest was presumed to be medical in origin, unless the cardiac arrest was due to trauma, drug overdose, drowning, electrocution, or asphyxia, according to the current Utstein Style template [21]. The aetiologies were determined clinically by the physicians in collaboration with EMS personnel.

\section{EMS Systems in Japan}

The Japanese paediatric population (aged 0-17 years) was approximately 20 million in 2015 [22], covering a geographic area of approximately $378,000 \mathrm{~km}^{2}$. EMS is provided by regional governments, and there were 750 fire stations with dispatch centres in 2015 [23]. Emergency life-saving technicians (ELSTs), who are highly trained emergency care providers, are allowed to start an intravenous line, provide an adjunct airway, and use semi-automated external defibrillators for OHCA patients. Specially trained ELSTs are allowed to intubate and administer adrenaline. Basically, each ambulance has a crew of three emergency providers, including at least one ELST. Cardiac arrest treatments were based on the Japanese CPR guidelines [24]. EMS providers are not permitted to terminate resuscitation in the field, excluding victims of decapitation, incineration, decomposition, rigor mortis, or dependent cyanosis. Thus, most OHCA patients treated by EMS personnel are transported to a hospital and included in the registry.

\section{Data collection and quality control}

Data on resuscitation-related factors were prospectively obtained, including date, sex, age, cause of arrest, first documented rhythm, witness of cardiac arrest, time course of resuscitation, bystander CPR, dispatcher instruction, defibrillations by public-access AEDs, epinephrine administration, advanced airway management, prehospital return of spontaneous circulation (ROSC), 1-month survival, and neurological status 1 month after the event. When bystanders provided shocks using a public-access AED, the patients' first documented rhythm was regarded as ventricular fibrillation (VF). In addition to the previous items of the international Utstein Style [19-21], the FDMA has started collecting detailed information on the location of OHCA occurrence since January 2013. According to the current Utstein Style 
template, locations of arrest are classified as follows: homes/residences, public areas, workplaces, recreation/ sports event areas, streets/highways, healthcare facilities (clinic/nursing home), educational institutions, and others [21].

All survivors were followed for up to 1 month after the OHCA event by the EMS providers in charge. The neurological outcome was determined by the physician responsible for the care of the patient by a follow-up interview 1 month after successful resuscitation using the cerebral performance category (CPC) scale: category 1 , good cerebral performance; category 2, moderate cerebral disability; category 3, severe cerebral disability; category 4, coma or vegetative state; and category 5, death/brain death [19-21].

A data form was filled out by the EMS personnel in cooperation with the physician in charge, and data were stored in the registry system on the FDMA database server. Data were logically checked via the computer system and were confirmed by the FDMA. If the data form was incomplete, the FDMA returned it to the respective fire station to complete the data.

\section{Outcome measures}

The primary outcome measure was 1-month survival with a favourable neurological outcome after OHCA, which is defined as CPC 1 or 2 [19-21]. The secondary outcome measures were prehospital ROSC and 1-month survival. ROSC was defined as the restoration of a sustained spontaneous perfusing rhythm [25].

\section{Statistical analysis}

Based on previous studies, prehospital EMS CPR duration was defined as the time from CPR initiation by EMS personnel to the time of prehospital ROSC (in cases where prehospital ROSC was achieved) or to the time of hospital arrival [26-29], and prehospital EMS CPR duration was classified into seven categories: $0-5$, $6-10,11-15,16-20,21-25,26-30$, and $\geq 31 \mathrm{~min}$. In this study, main analyses were performed separately by location of cardiac arrests ("residential locations" and "public locations"). We defined a "residential locations" as homes/residences and a "public locations" as either public arias, recreation/sports locations, street/highway, educational institutions, and other public places, using defined in the Utstein template [21].

Patient and EMS characteristics and their outcomes were compared between the groups using Mann-Whitney $U$ tests for numerical variables and chi-squared test for categorical variables. Furthermore, univariable and multivariable logistic regression analyses were applied to assess the association between prehospital EMS CPR duration and a favourable neurological outcome, and crude and adjusted odds ratios (AORs) and their 95\% confidence intervals (CIs) were calculated. As potential confounders, factors that were biologically essential and considered associated with clinical outcomes were included in the multivariable analysis based on previous studies $[8,9,26,27,29,30]$. These potential confounding variables were age groups $(0,1-4,5-12$, and $13-17$ years), sex (male, female), cause of arrest (medical, nonmedical), witness of arrest (yes, no), dispatcher instruction (yes, no), first documented rhythm (VF/pulseless ventricular tachycardia [VT], pulseless electrical activity [PEA], asystole), bystander CPR (yes, no), shocks by public-access AED (yes, no), epinephrine administration (yes, no), and advanced airway management (yes, no). In addition, as a subgroup analysis, we assessed the differences of the patient and EMS characteristics and their outcomes according to specific public locations. We applied the logistic regression analyses, using the same confounders with the main analyses. Public locations were divided into five groups: public areas, recreation/ sports locations, educational institutions, streets/highways, and other locations (e.g., rice fields, sea, mountain, and unknown). Moreover, bystander ROSC, which was defined as a prehospital EMS CPR duration of $0 \mathrm{~min}$, was added to prehospital EMS CPR duration categories. All statistical analyses were performed using SPSS statistical package 24.0 J (IBM Corp., Armonk, NY, USA). All tests were two-tailed, and $P$ values $<.05$ were considered statistically significant.

\section{Results}

During the study period, a total of 373,359 OHCA cases were registered, of which 3913 were paediatric OHCA patients and were analysed in this study [residential locations $(2865,73.2 \%)$ and public locations (1048, 26.8\%)] (Fig. 1).

Patient and EMS characteristics and outcomes of paediatric OHCA patients according to the location of arrest are shown in Table 1. Those who collapsed in residential locations were more likely to be younger, had cardiac arrests of medical origin, and had dispatcher instructions and bystander CPR; moreover, they were less likely to have a witness of arrest, first documented shockable rhythm, and shocks by public-access AEDs. Nevertheless, no significant difference in the median of prehospital EMS CPR duration between the groups was found.

Regarding the primary outcome, the proportion of patients with a favourable neurological outcome was $2.3 \%$ $(66 / 2865)$ in residential locations and $10.8 \%(113 / 1048)$ in public locations $(P<.001$; Table 1$)$. Table 2 shows the ORs for prehospital EMS CPR duration and favourable neurological outcome. In both residential and public locations, the prehospital EMS CPR duration was significantly and independently associated with a favourable 


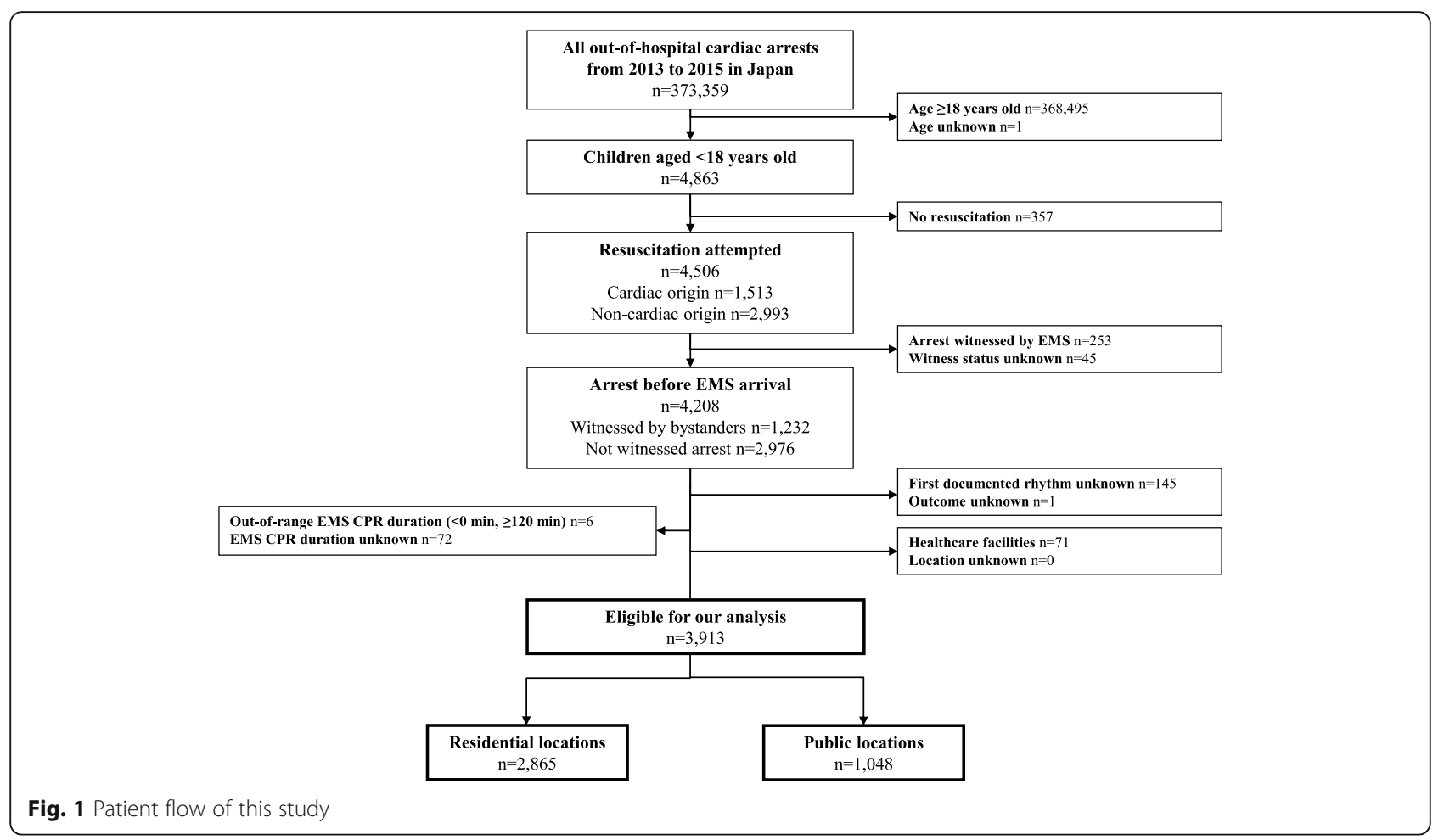

neurological outcome, and the proportion of patients with a favourable neurological outcome decreased as the prehospital EMS CPR duration increased $(P$ for trend $<.001)$. Moreover, the proportion of patients with a favourable neurological outcome in the group with a prehospital EMS CPR duration $\geq 31$ min was significantly lower than that in the group with a prehospital EMS CPR duration of $0-5 \mathrm{~min}$ (58.7\% [81/138] vs $1.2 \%$ [7/587], AOR $0.04,95 \%$ CI $0.02-0.11$ in all patients; $30.2 \%[16 / 53]$ vs 1.4 [6/417], AOR 0.07, 95\% CI $0.02-0.22$ in residential locations; and $76.5 \%$ [65/85] vs $0.6 \%$ [1/170], AOR 0.01, 95\% CI 0.00-0.08).

Table 3 shows the characteristics and outcomes of paediatric patients with OHCA in public locations. Those who had a cardiac arrest in recreation/sports locations and educational institutions were more likely to have bystander CPR, to be shocked using public-access AEDs, and to achieve prehospital ROSC. Hence, the median of prehospital EMS CPR duration was shorter, and the proportion of patients who had a favourable neurological outcome was higher. Table 4 shows the proportion of those with a favourable neurological outcome in public locations according to prehospital EMS CPR duration. In recreation/sports locations and educational institutions, the proportion of patients with a favourable neurological outcome in the groups with a short prehospital EMS CPR duration ( $<15 \mathrm{~min})$ was higher than that in other groups.

\section{Discussion}

Based on a nationwide, population-based OHCA registry in Japan, we demonstrated that a longer prehospital EMS CPR duration is independently associated with a lower proportion of patients with a favourable neurological outcome 1 month after the OHCA event. Nonetheless, some paediatric patients with a prehospital EMS CPR duration of $>30$ min survived with a better neurological outcome.

Regardless of the location of arrest, the outcomes deteriorated as prehospital EMS CPR duration increased. This finding was similar to those of previous studies $[26,29,31]$, which could be explained by the poor CPR quality and long CPR interruption as the duration increased. Moreover, several previous studies demonstrated that the prehospital CPR duration of most paediatric patients who survived after OHCA was $\leq 15 \mathrm{~min}$ [32]. In our study, the proportion of patients with a favourable neurological outcome decreased markedly in the group with a prehospital EMS CPR duration of $\geq 15 \mathrm{~min}$. Nevertheless, some paediatric patients with a prehospital EMS CPR duration of $>30$ min survived with better neurological outcome, although a prehospital CPR duration of $>30 \mathrm{~min}$ was an indicator of a poor outcome [32]. This finding could be partially explained by the improvement in the "chain of survival," such as dissemination of bystander $\mathrm{CPR}$, an increase in the number of public-access AEDs, advanced prehospital care, and differences in patient characteristics $[4,12,13,18]$. 
Table 1 Characteristics of out-of-hospital cardiac arrest among children by location of arrest

\begin{tabular}{|c|c|c|c|c|c|c|c|}
\hline \multirow{3}{*}{$\begin{array}{l}\text { Characteristics } \\
\text { Weekday, n (\%) }\end{array}$} & \multirow{2}{*}{\multicolumn{2}{|c|}{ Total }} & \multirow{2}{*}{\multicolumn{2}{|c|}{$\begin{array}{l}\text { Residential locations } \\
(N=2865)\end{array}$}} & \multirow{2}{*}{\multicolumn{2}{|c|}{$\begin{array}{l}\text { Public locations } \\
(N=1048)\end{array}$}} & \multirow{3}{*}{$\begin{array}{l}P \text { value }^{*} \\
.175\end{array}$} \\
\hline & & $(N=3913)$ & & & & & \\
\hline & 2756 & $(70.4)$ & 2035 & $(71.0)$ & 721 & $(68.8)$ & \\
\hline Age, median (IQR) & 2 & $(0-13)$ & 1 & $(0-10)$ & 9 & $(2-15)$ & $<.001$ \\
\hline Age group, n (\%) & & & & & & & $<.001$ \\
\hline 0 years old & 1504 & $(38.4)$ & 1320 & $(46.1)$ & 184 & $(17.6)$ & \\
\hline $1-4$ years old & 749 & $(19.1)$ & 582 & $(20.3)$ & 167 & $(15.9)$ & \\
\hline $5-12$ years old & 640 & $(16.4)$ & 374 & $(13.1)$ & 266 & $(25.4)$ & \\
\hline 13-17 years old & 1020 & $(26.1)$ & 589 & $(20.6)$ & 431 & $(41.1)$ & \\
\hline Male sex, n (\%) & 2399 & $(61.3)$ & 1668 & $(58.2)$ & 731 & $(69.8)$ & $<.001$ \\
\hline Origin, n (\%) & & & & & & & $<.001$ \\
\hline Medical & 2725 & $(69.6)$ & 2240 & $(78.2)$ & 485 & $(46.3)$ & \\
\hline Non-medical & 1188 & $(30.4)$ & 625 & $(21.8)$ & 563 & $(53.7)$ & \\
\hline Witnessed, n (\%) & 1065 & $(27.2)$ & 528 & $(18.4)$ & 537 & $(51.2)$ & $<.001$ \\
\hline Dispatcher instruction, n (\%) & 2497 & $(63.8)$ & 2048 & $(71.5)$ & 449 & $(42.8)$ & $<.001$ \\
\hline First documented rhythm, n (\%) & & & & & & & $<.001$ \\
\hline VFNT & 245 & $(6.3)$ & 62 & $(2.2)$ & 183 & $(17.5)$ & \\
\hline PEA & 578 & $(14.8)$ & 364 & $(12.7)$ & 214 & $(20.4)$ & \\
\hline Asystole & 3090 & $(79.0)$ & 2439 & $(85.1)$ & 651 & $(62.1)$ & \\
\hline Bystander CPR, n (\%) & 2340 & $(59.8)$ & 1795 & $(62.7)$ & 545 & $(52.0)$ & $<.001$ \\
\hline Shocks by public-access AEDs, n (\%) & 96 & $(2.5)$ & 5 & $(0.2)$ & 91 & $(8.7)$ & $<.001$ \\
\hline Epinephrine administration, n (\%) & 151 & (3.9) & 90 & $(3.1)$ & 61 & $(5.8)$ & .001 \\
\hline Advanced airway management, n (\%) & 509 & $(13.0)$ & 374 & $(13.1)$ & 135 & $(12.9)$ & .887 \\
\hline \multicolumn{8}{|l|}{ EMS resuscitation times, median (IQR), min } \\
\hline EMS response time (call to contact with the patient) & 8 & $(7-10)$ & 8 & $(7-10)$ & 8 & $(7-11)$ & .020 \\
\hline Hospital arrival time (call to hospital arrival) & 29 & $(23-37)$ & 28 & $(23-36)$ & 30 & $(24-39)$ & $<.001$ \\
\hline EMS CPR duration, median (IQR), min & 19 & $(13-26)$ & 19 & $(14-26)$ & 19 & $(12-26)$ & .076 \\
\hline Prehospital ROSC, n (\%) & 273 & $(7.0)$ & 124 & $(4.3)$ & 149 & $(14.2)$ & $<.001$ \\
\hline One-month survival, n (\%) & 498 & $(12.7)$ & 304 & $(10.6)$ & 194 & $(18.5)$ & $<.001$ \\
\hline CPC 1 or $2, \mathrm{n}(\%)$ & 179 & (4.6) & 66 & $(2.3)$ & 113 & (10.8) & $<.001$ \\
\hline
\end{tabular}

$A E D$ automated external defibrillator, $C P C$ cerebral performance category, $C P R$ cardiopulmonary resuscitation, EMS emergency medical service, IQR first to third quartile, $P E A$ pulseless electrical activity ROSC return of spontaneous resuscitation, VF ventricular fibrillation

${ }^{*}$ Comparisons between the two groups were evaluated with Mann-Whitney $\mathrm{U}$ tests for continuous variables and chi-square test for categorical variables

The proportion of paediatric patients with a favourable neurological outcome after OHCAs in public locations according to prehospital EMS CPR duration was higher than that in residential locations, which was almost consistent with the findings from previous studies [14-16]. Specifically, in public locations, $76.5 \%(65 / 85)$ of paediatric OHCA patients with a prehospital EMS CPR duration within $0-5 \mathrm{~min}$ had a favourable neurological outcome, which was a markedly high rate. Children with OHCA in public locations were more likely to have factors associated with a favourable neurological outcome, such as witness of arrest, first documented shockable rhythm, and shocks by a public-access AED, compared to those in residential locations $[6,8,9,12,13,26]$. In Japan, public-access AEDs have been installed (over 600,
000 devices in 2015) [33], and the Japan AED Project was launched in 2014 to further disseminate public-access defibrillation [34]; the project aims to encourage laypersons to learn how to administer CPR and use AEDs for OHCA patients via mass media and various medical associations across Japan. Thus, our results suggest that these various efforts in Japan led to achieving early ROSC and improving the neurological outcome of paediatric patients with OHCAs in public locations.

This study additionally investigated prehospital EMS CPR duration according to specific public locations and demonstrated that recreation/sports locations and educational institutions have a shorter prehospital EMS CPR duration and a better outcome. These public locations were more likely to have factors associated with a 


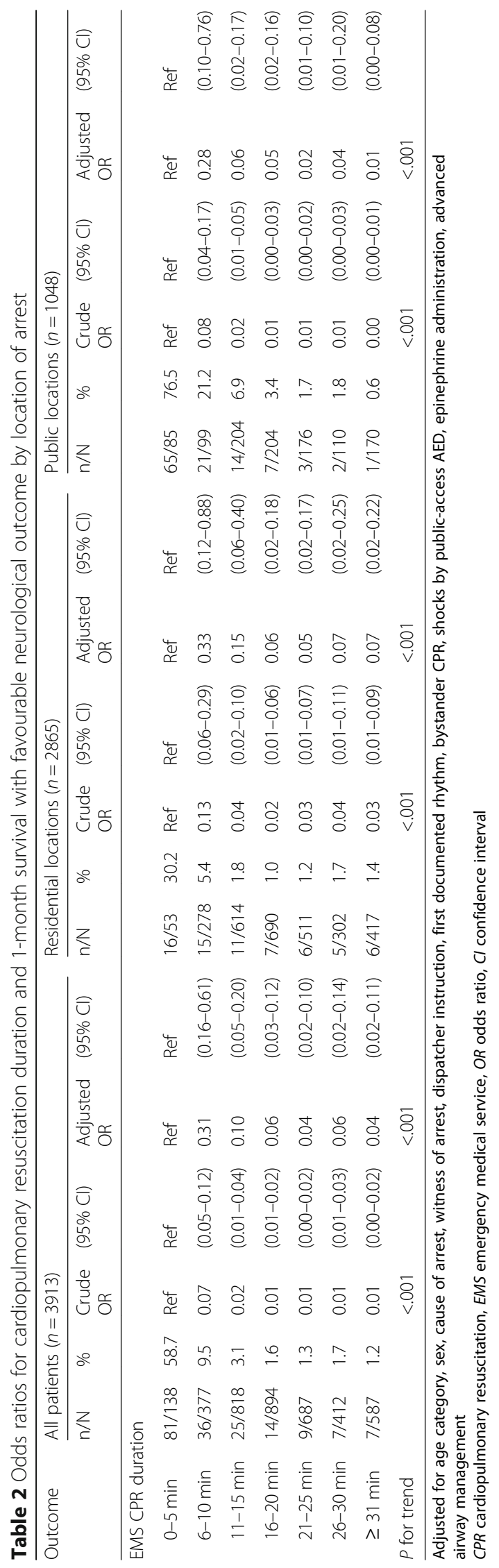


Table 3 Characteristics of out-of-hospital cardiac arrest among children by public locations of arrest

\begin{tabular}{|c|c|c|c|c|c|c|c|c|c|c|c|c|}
\hline \multirow{3}{*}{$\begin{array}{l}\text { Characteristics } \\
\text { Witnessed, n (\%) }\end{array}$} & \multirow{2}{*}{\multicolumn{2}{|c|}{$\begin{array}{l}\begin{array}{l}\text { Public locations } \\
\text { (total) }\end{array} \\
(n=1048)\end{array}$}} & \multirow{2}{*}{\multicolumn{2}{|c|}{$\begin{array}{l}\text { Public } \\
\text { areas } \\
(n=124)\end{array}$}} & \multirow{2}{*}{\multicolumn{2}{|c|}{$\begin{array}{l}\text { Recreation/sports } \\
\text { locations } \\
(n=49)\end{array}$}} & \multirow{2}{*}{\multicolumn{2}{|c|}{$\begin{array}{l}\text { Educational } \\
\text { institutions } \\
(n=166)\end{array}$}} & \multirow{2}{*}{\multicolumn{2}{|c|}{$\begin{array}{l}\text { Streets/highways } \\
(n=311)\end{array}$}} & \multirow{2}{*}{\multicolumn{2}{|c|}{$\begin{array}{l}\text { Other locations } \\
(n=398)\end{array}$}} \\
\hline & & & & & & & & & & & & \\
\hline & 537 & $(51.2)$ & 63 & $(50.8)$ & 21 & $(42.9)$ & 109 & $(65.7)$ & 226 & $(72.7)$ & 118 & $(29.6)$ \\
\hline Dispatcher instruction, n (\%) & 449 & $(42.8)$ & 54 & $(43.5)$ & 24 & $(49.0)$ & 95 & $(57.2)$ & 82 & $(26.4)$ & 194 & $(48.7)$ \\
\hline Bystander CPR, n (\%) & 545 & $(52.0)$ & 51 & $(41.1)$ & 38 & $(77.6)$ & 139 & (83.7) & 103 & (33.1) & 214 & $(53.8)$ \\
\hline Shocks by public-access AEDs, n (\%) & 91 & $(8.7)$ & 2 & (1.6) & 10 & $(20.4)$ & 72 & $(43.4)$ & 3 & $(1.0)$ & 4 & $(1.0)$ \\
\hline Prehospital ROSC, n (\%) & 149 & $(14.2)$ & 13 & $(10.5)$ & 11 & $(22.4)$ & 74 & $(44.6)$ & 31 & $(10.0)$ & 20 & $(5.0)$ \\
\hline EMS CPR duration, median (IQR), min & 19 & $(12-26)$ & 17 & $(13-26)$ & 15 & $(11-25)$ & 12 & $(2-20)$ & 20 & $(13-27)$ & 21 & $(15-28)$ \\
\hline One-month survival, n (\%) & 194 & $(18.5)$ & 25 & $(20.2)$ & 17 & $(34.7)$ & 83 & $(50.0)$ & 31 & $(10.0)$ & 38 & $(9.5)$ \\
\hline CPC 1 or $2, \mathrm{n}(\%)$ & 113 & $(10.8)$ & 11 & (8.9) & 11 & $(22.4)$ & 68 & $(41.0)$ & 13 & $(4.2)$ & 10 & (2.5) \\
\hline
\end{tabular}

$C P R$ cardiopulmonary resuscitation, $A E D$ automated external defibrillator, $R O S C$ return of spontaneous resuscitation, $C P C$ cerebral performance category, EMS emergency medical service, $I Q R$ first to third quartile

favourable neurological outcome, such as witness of arrest, bystander CPR, and shocks by a public-access AED compared to other public locations [4, 11-13]. In Japan, the statement "Aiming for zero deaths: Prevention of sudden cardiac death in schools and sport locations" published by the Japan Circulation Society [35, 36], CPR education, and widespread installation of AEDs in those locations are specific strategies that could result in a higher proportion of bystander interventions.

OHCAs in residential locations were more likely to have factors associated with a poor neurological outcome, such as age $<1$ year old, no witness of arrest, and no first documented shockable rhythm $[6,8,9,12,13$, $26,32]$, and the proportion of patients who had prehospital ROSC in residential locations was also lower in our study. Therefore, a longer prehospital EMS CPR duration for paediatric OHCA in residential locations seems futile. Moreover, in residential locations, the proportion of paediatric patients with a favourable neurological outcome in the group with a prehospital EMS CPR duration within $0-5$ min was half of or less than half that in public locations. Nevertheless, there were some paediatric patients in residential locations with a prehospital EMS CPR duration of $>30 \mathrm{~min}$ who survived with a good neurological outcome. Therefore, for paediatric OHCAs in residential locations, investigating who would benefit from receiving a prolonged EMS CPR duration is necessary.

This study has several limitations. First, we could not analyse the effect of the total CPR duration, i.e., including prehospital bystander CPR time prior to EMS arrival and in-hospital CPR duration. Also, we could not account for no-CPR duration before the initiation of CPR. Second, although we assessed the impact of EMS CPR duration by each location, the situation before the initiation of EMS CPR may vary according to the actual location, even if cardiac arrests occur in the same category of location. For example, EMS arrival times may be much longer and there may be a smaller number of bystanders in rural areas. This study could not adjust for these factors. Third, we did not obtain information about bystander CPR quality and in-hospital treatments.

Table 4 Cardiopulmonary resuscitation duration and 1-month survival with a favourable neurological outcome by public locations of arrest

\begin{tabular}{|c|c|c|c|c|c|c|c|c|c|c|}
\hline \multirow[t]{2}{*}{ Outcome } & \multicolumn{2}{|c|}{$\begin{array}{l}\text { Public areas } \\
(n=124)\end{array}$} & \multicolumn{2}{|c|}{$\begin{array}{l}\text { Recreation /Sports locations } \\
(n=49)\end{array}$} & \multicolumn{2}{|c|}{$\begin{array}{l}\text { Educational institutions } \\
(n=166)\end{array}$} & \multicolumn{2}{|c|}{$\begin{array}{l}\text { Streets/highways } \\
(n=311)\end{array}$} & \multicolumn{2}{|c|}{$\begin{array}{l}\text { Other locations } \\
(n=398)\end{array}$} \\
\hline & $\mathrm{n} / \mathrm{N}$ & $\%$ & $\mathrm{n} / \mathrm{N}$ & $\%$ & $\mathrm{n} / \mathrm{N}$ & $\%$ & $\mathrm{n} / \mathrm{N}$ & $\%$ & $\mathrm{n} / \mathrm{N}$ & $\%$ \\
\hline \multicolumn{11}{|l|}{ EMS CPR duration } \\
\hline Bystander ROSC & $0 / 1$ & 0.0 & $6 / 6$ & 100 & $35 / 38$ & 92.1 & $0 / 2$ & 0.0 & $0 / 1$ & 0.0 \\
\hline $1-5 \min$ & $0 / 2$ & 0.0 & $3 / 3$ & 100 & $15 / 15$ & 100 & $4 / 11$ & 36.4 & $2 / 6$ & 33.3 \\
\hline 6-10 min & $2 / 18$ & 11.1 & $0 / 3$ & 0.0 & $9 / 16$ & 56.3 & $4 / 32$ & 12.5 & $6 / 30$ & 20.0 \\
\hline $11-15 \mathrm{~min}$ & $5 / 28$ & 17.9 & $2 / 14$ & 14.3 & $5 / 31$ & 16.1 & $2 / 63$ & 3.2 & $0 / 68$ & 0.0 \\
\hline $16-20 \mathrm{~min}$ & $3 / 24$ & 12.5 & $0 / 7$ & 0.0 & $2 / 25$ & 8.0 & $2 / 57$ & 3.5 & $0 / 91$ & 0.0 \\
\hline $21-25 \min$ & $0 / 19$ & 0.0 & $0 / 6$ & 0.0 & $1 / 20$ & 5.0 & $1 / 58$ & 1.7 & $1 / 73$ & 1.4 \\
\hline $26-30 \mathrm{~min}$ & $1 / 11$ & 9.1 & $0 / 3$ & 0.0 & $0 / 8$ & 0.0 & $0 / 31$ & 0.0 & $1 / 57$ & 1.8 \\
\hline$\geq 31 \mathrm{~min}$ & $0 / 21$ & 0.0 & $0 / 7$ & 0.0 & $1 / 13$ & 7.7 & $0 / 57$ & 0.0 & $0 / 72$ & 0.0 \\
\hline
\end{tabular}

CPR cardiopulmonary resuscitation, ROSC return of spontaneous circulation, EMS emergency medical service 
Finally, although we adjusted for covariates, the possibility remains of having some unmeasured confounding factors that could influence the results. Nevertheless, this was the first study to demonstrate the relationship between prehospital EMS CPR duration and 1-month survival with a favourable neurological outcome according to the location of arrest among paediatric OHCA patients. The results of this study could provide helpful clues for improving the treatment strategy for paediatric OHCAs.

\section{Conclusions}

On the basis of a nationwide, population-based OHCA registry in Japan and regardless of the location of arrest, a longer prehospital EMS CPR duration for paediatric patients with OHCAs was independently associated with a lower proportion of patients having favourable neurological outcomes 1 month after the arrest. However, the association between prehospital EMS CPR duration and neurological outcome differed significantly according to the location of arrest.

\section{Abbreviations}

AEDs: Automated external defibrillators; AORs: Adjusted odds ratios; Cls: Confidence intervals; CPC: Cerebral performance category; CPR: Cardiopulmonary resuscitation; ELSTs: Emergency life-saving technicians; EMS: Emergency medical services; FDMA: Fire and Disaster Management Agency; OHCA: Out-of-hospital cardiac arrest; PEA: Pulseless electrical activity; ROSC: Return of spontaneous circulation; VF: Ventricular fibrillation; $\mathrm{VT}$ : Ventricular tachycardia

\section{Acknowledgements}

We are greatly indebted to all the EMS personnel and concerned physicians in Japan. We would also like to express our appreciation to the Fire and Disaster Management Agency and the Institute for Fire Safety and Disaster Preparedness of Japan for their generous cooperation in establishing and maintaining the Utstein database.

\begin{abstract}
Authors' contributions
HS analysed the data and wrote the first draft of the manuscript. TM reviewed all statistical analyses and critically revised the manuscript. KK, TKitamura, TKishimori, TKiguchi, CN, DK, SO, TS, and TM interpreted the data and critically revised the manuscript. TI acquired the data. TM, KK, TKitamura, and TI acquired the funding. TI and TKawamura supervised the data interpretation and critically revised the manuscript. All the authors read and approved the final manuscript.
\end{abstract}

\section{Funding}

This study was supported by a research grant from Pfizer Health Research Foundation (Grant Number 18-Y-13). This work was also supported by Otsuma Grant-in-Aid for Individual Exploratory Research (Grant Number S3012).

\section{Availability of data and materials}

The data that support the findings of this study are available from the FDMA of Japan, but the availability of these data is restricted.

\section{Ethics approval and consent to participate}

The Ethics Committee of Kyoto University Graduate School of Medicine and Osaka University Graduate School of Medicine approved this registry study. Written informed consent requirement was waived.

\section{Consent for publication}

Not applicable.

\section{Competing interests}

The authors declare that they have no competing interests

\section{Author details}

${ }^{1}$ Department of Preventive Services, Kyoto University School of Public Health, Kyoto, Japan. ${ }^{2}$ Department of Emergency Medicine, Kyoto Prefectural University of Medicine, Kyoto, Japan. ${ }^{3}$ Department of Food Science, Otsuma Women's University, Tokyo, Japan. ${ }^{4}$ Division of Environmental Medicine and Population Sciences, Department of Social and Environmental Medicine, Graduate School of Medicine, Osaka University, Osaka, Japan. ${ }^{5}$ Kyoto University Health Services, Kyoto, Japan. ${ }^{6}$ Department of Critical Care Nursing, Kyoto University Graduate School of Human Health Science, Kyoto, Japan.

Received: 5 May 2019 Accepted: 14 August 2019

Published online: 23 August 2019

\section{References}

1. Neumar RW, Shuster M, Callaway CW, Gent LM, Atkins DL, Bhanji F, et al. Part 1: executive summary: 2015 American Heart Association guidelines update for cardiopulmonary resuscitation and emergency cardiovascular care. Circulation. 2015;132:S315-7.

2. Monsieurs KG, Nolan JP, Bossaert LL, Greif R, Maconochie IK, Nikolaou NI, et al. European resuscitation council guidelines for resuscitation 2015: section 1. Executive summary. Resuscitation. 2015;95:1-80.

3. Hazinski MF, Nolan JP, Aickin R, Bhanji F, Billi JE, Callaway CW, et al. Part 1: executive summary: 2015 international consensus on cardiopulmonary resuscitation and emergency cardiovascular care science with treatment recommendations. Circulation. 2015;132:52-39.

4. Kitamura T, Iwami T, Kawamura T, Nagao K, Tanaka H, Nadkarni VM, et al. Conventional and chest-compression-only cardiopulmonary resuscitation by bystanders for children who have out-of-hospital cardiac arrests: a prospective, nationwide, population-based cohort study. Lancet. 2010;375:1347-54

5. Nitta M, Iwami T, Kitamura T, Nadkarni VM, Berg RA, Shimizu N, et al. Age -specific differences in outcomes after out-of-hospital cardiac arrests. Pediatrics. 2011;128:e812-20.

6. Atkins DL, Everson-Stewart S, Sears GK, Daya M, Osmond MH, Warden CR, et al. Epidemiology and outcomes from out-of-hospital cardiac arrest in children: the resuscitation outcomes consortium Epistry-cardiac arrest. Circulation. 2009;119:1484-91.

7. Young KD, Gausche-Hill M, McClung CD, Lewis RJ. A prospective, population-based study of the epidemiology and outcome of out-ofhospital pediatric cardiopulmonary arrest. Pediatrics. 2004;114:157-64.

8. Goto Y, Funada A, Nakatsu-Goto Y. Neurological outcomes in children dead on hospital arrival. Crit Care. 2015;19:410.

9. Goto Y, Maeda T, Nakatsu-Goto Y. Decision tree model for predicting long -term outcomes in children with out-of-hospital cardiac arrest: a nationwide population-based observational study. Crit Care. 2014;18:R133.

10. Maconochie IK, de Caen AR, Aickin R, Atkins DL, Biarent D, Guerguerian AM, et al. Part 6: pediatric basic life support and pediatric advanced life support: 2015 international consensus on cardiopulmonary resuscitation and emergency cardiovascular care science with treatment recommendations. Resuscitation. 2015;95:e147-68.

11. Naim MY, Burke RV, McNally BF, Song L, Griffis HM, Berg RA, et al. Association of bystander cardiopulmonary resuscitation with overall and neurologically favorable survival after pediatric out-of-hospital cardiac arrest in the United States: a report from the cardiac arrest registry to enhance survival surveillance registry. JAMA Pediatr. 2017;171:133-41.

12. Kiyohara K, Sado J, Kitamura T, Ayusawa M, Nitta M, Iwami T, et al. Public -access automated external defibrillation and bystander-initiated cardiopulmonary resuscitation in schools: a nationwide investigation in Japan. Europace. 2019;21:451-8.

13. Kiyohara K, Nitta M, Sato Y, Ayusawa M, Nitta M, Iwami T, et al. Ten-year trends of public-access defibrillation in Japanese school-aged patients having neurologically favorable survival after out-of-hospital cardiac arrest. Am J Cardiol. 2018;122:890-7.

14. Iwami T, Hiraide A, Nakanishi N, Hayashi Y, Nishiuchi T, Uejima T, et al. Outcome and characteristics of out-of-hospital cardiac arrest according to location of arrest: a report from a large-scale, population-based study in Osaka, Japan. Resuscitation. 2006;69:221-8. 
15. Weisfeldt ML, Everson-Stewart S, Sitlani C, Rea T, Aufderheide TP, Atkins DL, et al. Ventricular tachyarrhythmias after cardiac arrest in public versus at home. N Engl J Med. 2011;364:313-21.

16. Folke F, Gislason GH, Lippert FK, Nielsen SL, Weeke P, Hansen ML, et al. Differences between out-of-hospital cardiac arrest in residential and public locations and implications for public-access defibrillation. Circulation. 2010;122:623-30.

17. Kitamura T, Iwami T, Kawamura T, Nagao K, Tanaka H, Hiraide A. Implementation working Group for the all-Japan Utstein Registry of the fire and disaster management agency. Nationwide public-access defibrillation in Japan. N Engl J Med. 2010;362:994-1004.

18. Kitamura T, Kiyohara K, Sakai T, Matsuyama T, Hatakeyama T, Shimamoto T, et al. Public-access defibrillation and out-of-hospital cardiac arrest in Japan. N Engl J Med. 2016;375:1649-59.

19. Cummins RO, Chamberlain DA, Abramson NS, Allen M, Baskett PJ, Becker L, et al. Recommended guidelines for uniform reporting of data from out-ofhospital cardiac arrest: the Utstein style. A statement for health professionals from a task force of the American Heart Association, the European resuscitation council, the Heart and Stroke Foundation of Canada, and the Australian resuscitation council. Circulation. 1991;84:960-75.

20. Jacobs I, Nadkarni V, Bahr J, Berg RA, Billi JE, Bossaert L, et al. Cardiac arrest and cardiopulmonary resuscitation outcome reports: update and simplification of the Utstein templates for resuscitation registries: a statement for healthcare professionals from a task force of the international liaison committee on resuscitation (American Heart Association, European resuscitation council, Australian resuscitation council, New Zealand resuscitation council, Heart and Stroke Foundation of Canada, InterAmerican Heart Foundation, resuscitation councils of southern Africa). Circulation. 2004;110:3385-97.

21. Perkins GD, Jacobs IG, Nadkarni VM, Berg RA, Bhanji F, Biarent D, et al. Cardiac arrest and cardiopulmonary resuscitation outcome reports: update of the Utstein resuscitation registry templates for out-of-hospital cardiac arrest: a statement for healthcare professionals from a task force of the international liaison committee on resuscitation (American Heart Association, European resuscitation council, Australian and New Zealand council on resuscitation, Heart and Stroke Foundation of Canada, InterAmerican Heart Foundation, resuscitation Council of Southern Africa, resuscitation Council of Asia); and the American Heart Association emergency cardiovascular care committee and the council on cardiopulmonary, critical care, perioperative and resuscitation. Circulation. 2015;132:1286-300.

22. Japan Government 2015 Report on National Census. https://www.stat.go.jp/ data/kokusei/2015/kekka.html. Accessed 26 July 2018.

23. Ambulance service planning Office of Fire and Disaster Management Agency of Japan. In: Effect of first aid for cardiopulmonary arrest; 2017 http://www.fdma.go.jp/html/hakusho/h28/h28/html/2-1-1-1.html. Accessed 26 July 2018.

24. Japan Resuscitation Council. 2015 Japanese guidelines for emergency care and cardiopulmonary resuscitation. Tokyo: Health Shuppansha; 2015.

25. Kajino K, Iwami T, Daya M, Nishiuchi T, Hayashi Y, Ikeuchi H, et al. Subsequent ventricular fibrillation and survival in out-of-hospital cardiac arrests presenting with PEA or asystole. Resuscitation. 2008;79:34-40.

26. Goto Y, Funada A, Goto Y. Duration of prehospital cardiopulmonary resuscitation and favorable neurological outcomes for pediatric out-ofhospital cardiac arrests: a nationwide, population-based cohort study. Circulation. 2016;134:2046-59.

27. Nagao K, Nonogi H, Yonemoto N, Gaieski DF, Ito N, Takayama M, et al. Duration of prehospital resuscitation efforts after out-of-hospital cardiac arrest. Circulation. 2016;133:1386-96.

28. Rajan S, Folke F, Kragholm K, Hansen CM, Granger CB, Hansen SM, et al. Prolonged cardiopulmonary resuscitation and outcomes after out-ofhospital cardiac arrest. Resuscitation. 2016;105:45-51.

29. Matsuyama T, Kitamura T, Kiyohara K, Nishiyama C, Nishiuchi T, Hayashi Y, et al. Impact of cardiopulmonary resuscitation duration on neurologically favourable outcome after out-of-hospital cardiac arrest: a population-based study in Japan. Resuscitation. 2017;113:1-7.

30. Kitamura T, Iwami T, Kawamura T, Nitta M, Nagao K, Nonogi H, et al. Nationwide improvements in survival from out-of-hospital cardiac arrest in Japan. Circulation. 2012;126:2834-43.

31. Kashiura M, Hamabe $Y$, Akashi A, Sakurai A, Tahara Y, Yonemoto N, et al. Association between cardiopulmonary resuscitation duration and one -month neurological outcomes for out-of-hospital cardiac arrest: a prospective cohort study. BMC Anesthesiol. 2017;17:59.

32. Young KD, Seidel JS. Pediatric cardiopulmonary resuscitation: a collective review. Ann Emerg Med. 1999:33:195-205.

33. Japan Heart Foundation, Dissemination of AED in Japan. https://www.jhf.or. jp/aed/spread.html. Accessed 28 Nov 2018.

34. Japan AED Project. Japan AED Project 2015. http://aed-project.jp/index.html. Accessed 28 Nov 2018

35. Mitamura H, Iwami T, Mitani Y, Takeda S, Takatsuki S. Aiming for zero deaths: prevention of sudden cardiac death in schools--statement from the AED Committee of the Japanese Circulation Society. Circ J. 2015;79:1398-401.

36. The Japanese Circulation Society. www.j-circ.or.jp/topics/aed_teigen.htm. Accessed 28 Nov 2018

\section{Publisher's Note}

Springer Nature remains neutral with regard to jurisdictional claims in published maps and institutional affiliations.
Ready to submit your research? Choose BMC and benefit from:

- fast, convenient online submission

- thorough peer review by experienced researchers in your field

- rapid publication on acceptance

- support for research data, including large and complex data types

- gold Open Access which fosters wider collaboration and increased citations

- maximum visibility for your research: over $100 \mathrm{M}$ website views per year

At $\mathrm{BMC}$, research is always in progress.

Learn more biomedcentral.com/submissions 